\title{
Lessons Learned from the COVID-19 Pandemic Exposing the Shortcomings of Current Supply Chain Operations: A Long-Term Prescriptive Offering
}

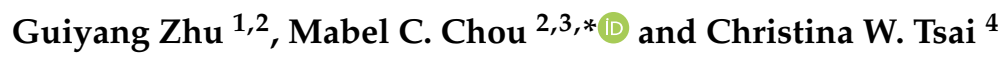 \\ 1 School of Management, Xi'an Jiaotong University, Xi'an 710049, China; zhuguiyang@stu.xjtu.edu.cn \\ 2 Institute of Operations Research and Analytics, National University of Singapore, \\ Singapore 117602, Singapore \\ 3 Department of Analytics and Operations, NUS Business School, National University of Singapore, \\ Singapore 119245, Singapore \\ 4 Department of Civil Engineering, National Taiwan University, Taipei 10617, Taiwan; cwstsai@ntu.edu.tw \\ * Correspondence: mabelchou@nus.edu.sg
}

Received: 13 May 2020; Accepted: 15 July 2020; Published: 21 July 2020

\begin{abstract}
COVID-19 is a highly infectious respiratory virus that has posed a great threat to the general public. In order to prevent its spread, many governments have enacted stringent measures. Supply chains around the world are facing major disruptions and difficulties adjusting to the new demands and needs of a locked down world. In this paper, we will address the relationship between supply chain operations and the ongoing COVID-19 pandemic. Given current global shortages in essential goods such as medication, we explore the connection between said shortage and supply chain issues, such as the lack of supply chain transparency and resilience, as well as unsustainable just-in-time manufacturing. To mitigate the effects of these issues and protect supply chain operations, we propose some recommendations, such as nationalizing the medical supply chains, adopting a plus one diversification approach, and increasing safety stock. These recommendations are given to not only mitigate current consequences in relation to the ongoing crisis, but also to suggest measures that will provide firms the resiliency needed to weather similar potential shortages in the future.
\end{abstract}

Keywords: COVID-19; supply chain disruptions; risk management; resilience

\section{Introduction}

The coronavirus disease 2019, also known as COVID-19, is a highly infectious respiratory virus that was first identified in the Chinese province of Hubei in December 2019. Given its high levels of transmission and danger to the general public, many governments have enacted stringent measures in order to prevent its spread. The ensuing response from both the general population and businesses to this crisis has resulted in an unprecedented event that some experts fear will have severe implications for the world economy [1]. In early March, the World Health Organization declared that the coronavirus outbreak had become a pandemic given its severe global impact [2].

Given the current social and economic landscape, supply chains around the world are facing major disruptions and difficulties adjusting to the new demands and needs of a locked down world. A recent report published in April 2020 has found that $94 \%$ of Fortune 1000 companies are experiencing disruptions as a result of COVID-19, while 75\% have been negatively affected [3]. According to the report by the International Civil Aviation Organization (ICAO) in 2020 [4], supply chain activities have been affected significantly due to COVID-19. Figure 1 shows that the world's GDP has declined tremendously due to economic disruptions triggered by COVID-19. In addition, as shown in Figure 2, the transport of people and goods worldwide has declined tremendously, and the aviation industry 
has faced a very serious crisis. Last but not least, global merchandise trade values have also declined significantly due to COVID-19, as shown in Figure 3 by the United Nations Conference on Trade and Development (UNCTAD) [5]. Indeed, the COVID-19 pandemic has affected many businesses around the world. From national lockdowns to closed borders, COVID-19 has disrupted economies and also placed major strains on global supply chains and demonstrated how fragile and vulnerable the modern supply chain can be to disruptions. As such, there is a growing need and pressure for companies to build "resilient" supply chains. It is hence becoming increasingly apparent, considering news of shortages worldwide, that the issue of a fragile and unsteady global supply chain needs to be resolved in order to not only weather the current pandemic, but also to prepare for potential disruptions of a similar scale in the future.

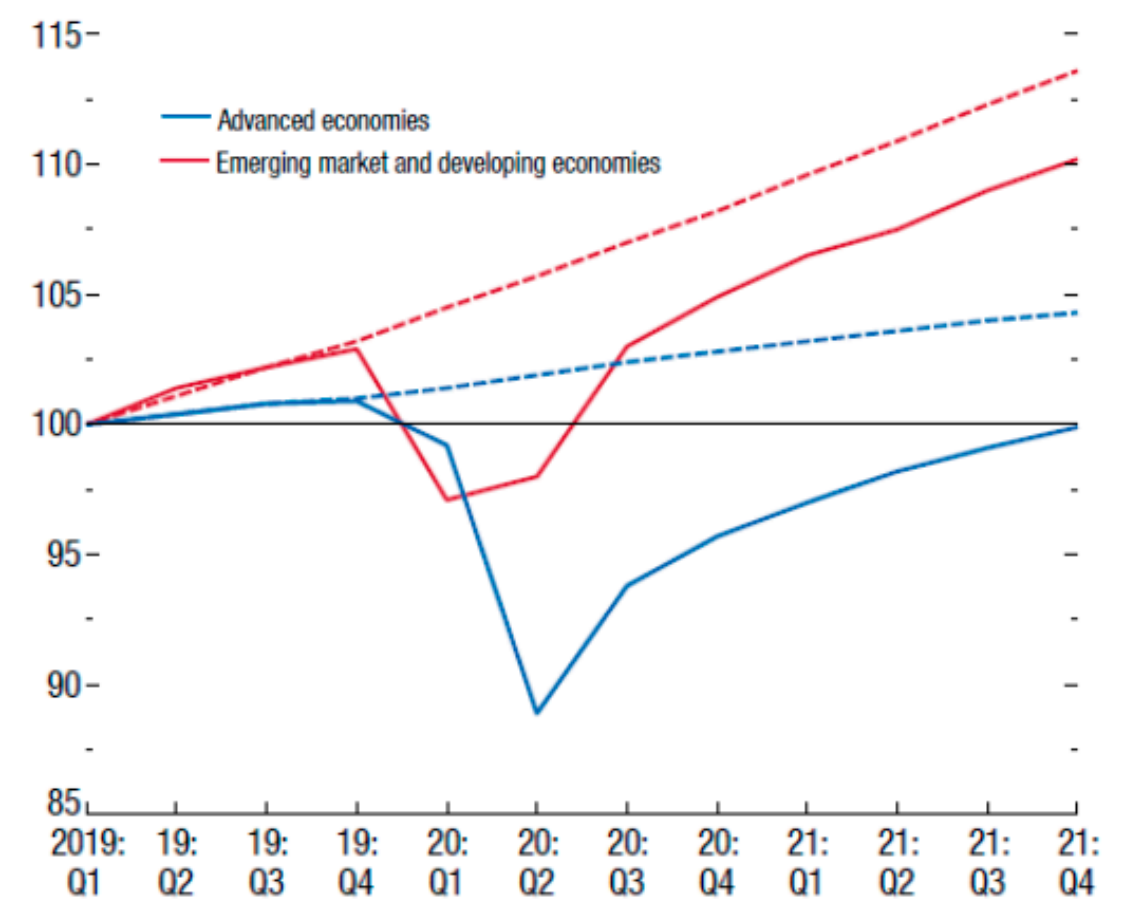

Figure 1. World's GDP projections (2019: Q1 = 100; dashed lines indicate estimates from January 2020 World Economic Outlook Update).

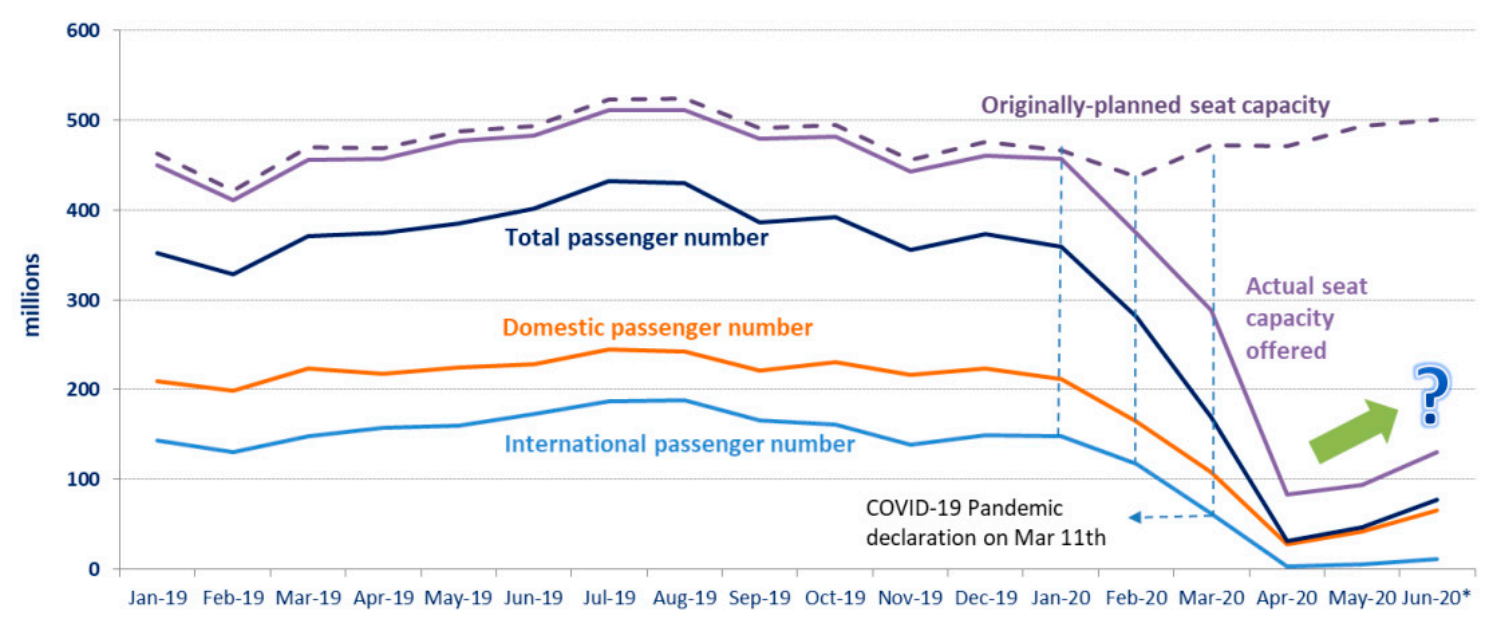

Figure 2. Drastic capacity cut along with dramatic drop in demand. 


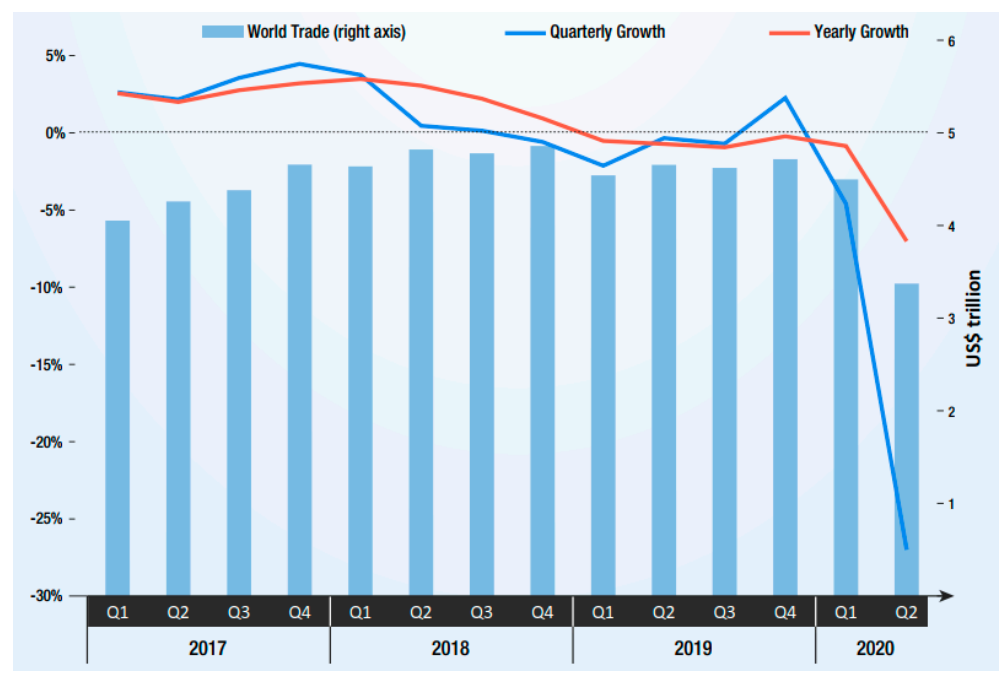

Figure 3. A steep downturn in global trade in goods (the value of international trade in goods has declined by about 5 percent in Q1 2020 and is expected to decline further by 27 percent in Q2 2020).

There have been many discussions on how COVID-19 has impacted global supply chains and some of the measures that companies or countries have taken or are going to take to transform their supply chain models. In the following, we review various aspects of these discussions. In particular, we review the discussions on the impact of COVID-19 on businesses in Section 1.1, and review how businesses are transforming their supply chains in Section 1.2. We give special attention to medical supply chains in Section 1.3 and water-energy-food (WEF) supply chains in Section 1.4 since these two supply chain types are closely related to essential needs and have significant impact on public health and wellness. Finally, we review the discussions related to predictions and preparations for the second wave of COVID-19 in Section 1.5. We conclude Section 1 with a clarification on the focus and range of our study, as well as the composition of the paper in Section 1.6.

\subsection{Impact of COVID-19 on Businesses}

In this section, we will highlight some of the impacts COVID-19 had on the global supply chain that brought about the need to build "resilient" supply chains.

Supply shocks. COVID-19 has adversely affected the supply of inputs for many businesses. With lockdown policies affecting the movement of people and business operations, Parsons [6] highlighted how the plants in China involuntarily sat idle as a result of COVID-19, which led to a diminishing global pipeline of parts and components going around the world. Manufacturers and retailers around the world who relied on inputs from these factories consequently could not acquire sufficient raw materials for their businesses.

Demand shocks/Higher variability in demand. People around the world have resorted to panic buying and stockpiling efforts in fear of food shortages during this trying period. This stockpiling behavior witnessed from people around the globe has rendered variability in demand for businesses. While it is a good sign for bigger companies to increase their sales during this period, Parsons [6] highlighted how this variability is difficult for smaller businesses to handle as they do not have the level of scale and versatility needed to maintain an acceptable level of product supply during demand shocks.

Bullwhip effect. The bullwhip effect refers to increasing swings in inventories in response to shifts in customer demand as one moves further up the supply chain. One of the main reasons why the bullwhip effect occurs is due to the lack of transparency in the supply chain. In this pandemic, businesses are well aware of demand fluctuations due to panic buying or stockpiling efforts. Therefore, one may think that the bullwhip effect will not be amplified in this case. However, Seifert and 
Markoff [7] stated that there is one classic cause of the bullwhip effect that needs to be handled-the "shortage gaming" effect. This effect explains how downstream players appear to falsely inflate their supply needs to demand a larger share of a scare resource when they anticipate supply shortages. As a result, demand patterns are even more unpredictable during this pandemic.

Transportation requirements/costs. Henriksen and Selwyn [8] pointed out how the potential of several occupations essential for the safe and continued operations of global supply chains are undermined due to closed borders and quarantine laws. These personnel rely on their movement across land and sea to keep global supply chains running. In response, a globally adopted status of "key worker" would grant such workers the right to transit international borders and to medical care ashore. This is pivotal in ensuring the reliable delivery of essential supplies.

Businesses that are looking to transport raw materials or final goods demand cargo space by air. However, to restrict the movement of people around the globe, commercial flights have been suspended due to COVID-19. With suspended or decreased passenger flights, freight that is typically borne by these flights must find alternate modes of transport, which is also difficult due to travel restrictions and closed borders. As a result, global air freight costs have been going up. Shira [9] mentioned that though the number of cargo flights has increased, it is still not sufficient to meet the demand. The need for a secure transportation network has put the global supply chain in a vulnerable position. Shira [9] also indicated that even though some borders remain open, custom procedures and approvals take a significant amount of time due to extended safety measures. These measures inevitably increase delays and costs for the suppliers.

\subsection{How Businesses Are Transforming the Modern Supply Chain}

We saw how COVID-19 brought about many uncertainties and risk to businesses whose success of their supply chains is reliant on external factors. This pandemic has highlighted to companies the urgent need to transform their supply chain models to withstand any disruptions in the future. Some companies have already begun building more resilient supply chains while others are forced to as a result of this pandemic. In the rest of Section 1.2, we will look at some of the measures that companies have taken or are planning to take to transform their supply chain models and compare between some of these approaches.

\subsubsection{Risk Management}

\section{Diversification/Dual Sourcing}

Many companies are forced to look for alternatives when China, the world's factory, shuts down its plants and factories during COVID-19. This is not doubted as the supply chains of many companies are reliant on China's ecosystem. Businesses have learnt the hard way of heavily relying on China's economy through this pandemic. In response, CEOs of many companies requested for their supply chain teams to find other sources wholly independent of China. There was also increasing pressure from investors and government bodies who discouraged over-reliance on any one source and called for decoupling from China. Based on an article from Oxford Business Group [10], COVID-19 has intensified the trend of US companies trying to realign supply chains closer to home in countries such as Mexico, while also diversifying them to mitigate potential risks by shifting to Association of Southeast Asian Nations (ASEAN) states, such as Vietnam, Indonesia, Thailand, and Malaysia. Maybank Kim Eng [11] also reported in February 2020 that large Asian companies such as Honda and Samsung had already started to mitigate risks by expanding their sources beyond just China.

However, alternative views suggest that these diversification efforts may take a long time or may not be feasible or favorable for certain companies [12]. In addition, companies also need to consider the perspectives of their investors [13]. In fact, as much as how this pandemic has brought about vulnerabilities of the modern supply chain, some companies still prefer China as a manufacturing location. Based on an article by The Japan Times [14], China remains popular as a manufacturing location 
due to its huge and expanding domestic market, competent labor, the entrenched supplier ecosystem, as well as the government's continued assistance towards manufacturers and the establishment of dependable infrastructure.

Vertical Integration of Supply Chains

$\mathrm{Yu}$ [15] reported that certain bigger companies will also integrate vertically throughout the value chain beyond China to seize autonomy over costs, quality, and supplies of inputs.

\section{Decentralization of Manufacturing Capacity}

$\mathrm{Yu}$ [15] reported the trend among companies to decentralize manufacturing capacity as they want to localize production and deploy automation and small batch manufacturing to reduce costs as these are now much cheaper options.

\section{Emphasis on Supply Chain Visibility}

Before this pandemic, supply chain risk management adopted by companies often only applied to top-tier suppliers. This made them susceptible to shocks involving their "invisible" lower-tier suppliers, which can rapidly instigate issues throughout the whole supply chain [16]. Staff [17] stated that it is pivotal to consider these lower-tier suppliers since they might have encountered problems that companies would not otherwise be aware of.

Sheffi [18] suggested that companies should conduct a comprehensive mapping of their supply chain in order to predict and prepare for disruptions from the supply side. The mapping should comprise not only the pinpointing of the company's immediate suppliers, but also indicating geographical locations of manufacturers' plants and factories. This is to specify and classify the products' risks by location and in a timely manner. Companies should be aware of their entire supply chain network and interplay between their supply chain players to effectively plan for and mitigate risks in the event of such a disruption like COVID-19.

\section{Localizing Supply Chains}

More and more companies are considering bringing manufacturing in-house or closer to home. Lin and Lanng [19] also stated that policymakers are more compelled to decide whether to manufacture certain products in the country or region. With the COVID-19 pandemic affecting the global supply chain and how many supply chain networks are reliant on China, it will be a wise decision to localize some parts of the supply chain, if not all. Larson [20] reported that local suppliers incurring lesser intermediaries can also accelerate business processes. From the angle of logistics and distribution, this enables companies to develop a nimble and adaptable supply chain network.

Besides the decision to localize production from a bottom line and risk perspective, companies are also choosing to do so due to changes in consumers' tastes and preferences. Larson [20] stated how consumers are progressively more mindful of the products' origins, and the ethical and environmental aspects that go into the manufacturing process. He mentioned that the decision to localize production can help companies to address these issues and win the likes of consumers, and at the same time, establish transparency in their supply chains. This is often a competitive factor that can be used to set their businesses apart from competitors.

Merging of B2B (Business-to-Business) and B2C (Business-to-Consumer)/Flexibility in Supply Chains

In times of crisis, we can see how certain businesses are able to adapt easily to suit demand and market needs, even if it was not their product offering in the first place. Rheude [21] reported how the limits of companies are stretched, as we see instances where companies adapted and served a new and different group of customers to stay in business or when businesses ventured into the online space in light of lockdown policies. All these are possible when a company develops their supply chain to be 
one that is flexible and readily available to respond to changing demands. Rheude [21] further stated that by adapting to both B2B and B2C markets and other modes of channels, companies and their supply chain networks may be able to thrive in uncertain and volatile environments and outperform their capabilities while also discovering new sales and growth opportunities.

\section{Managing Supply Shortfalls}

Due to supply chain disruption in times like COVID-19, companies may have to allocate their resources wisely to fulfil orders, depending on their priorities and trade-offs. Analytics Magazine News [22] stated that businesses have to evaluate and anticipate the effect of COVID-19 on customer needs and product availability. While there are many ways to evaluate one's priorities and make trade-off decisions, Sheffi [23] came up with six tactics to manage supply shortfalls and also established the scope and time horizon framework to weigh the consequences of the options.

\subsubsection{Other Measures}

Internal Measures

Investing in Online Distribution Channels. Samuel [24] pointed out that with increasing numbers of consumers working and staying at home, it will be imperative to explore opportunities to reach out to these customers virtually. While traditional brick-and-mortar stores are still relevant, companies should also delve into ways to interact and deliver directly to consumers. Some examples would be expanding into the online space or offering home delivery services.

Digital Transformation of Supply Networks. With the advancement of technology and how COVID-19 has brought about vulnerabilities in the supply chain, companies are looking to transform the traditional supply chain into digital supply networks (DSNs), where there is free flow of information and end-to-end visibility, corporation, dexterity, and optimization of the supply chain. Kilpatrick [25] stated that since DSNs are catered to envisage and tackle future challenges by tapping on advanced technologies such as the Internet of Things, artificial intelligence, robotics, and 5G, companies can be assured that they are able to overcome similar disruptions like COVID-19 in future and deal with market uncertainty and supply chain problems. It is clear that DSNs are the solution to a resilient supply chain moving forward as visibility is key to resilience [26].

Larson [20] also mentioned that DSNs can support a company's road to a flexible and adaptable supply chain. By tapping on new technology, companies are able to adapt their offerings quickly in times of changing preferences or environments to reach out to new or existing customers. However, as much as DSNs are advocated to build a more resilient supply chain, Wuest et al. [27] pointed out some of the challenges in implementing this as a long-term solution such as the need for high data quality as well as skilled labor to drive these Artificial Intelligence related processes forward. Smaller companies also lack the resources to proceed with DSNs. Hence, it is the responsibility of policymakers and government bodies to support and accelerate the journey of these smaller companies in their transformation to DSNs.

Digitizing the relationship between the buyer and the supplier is also a core aspect for developing robust supply chains and the time taken to pinpoint new suppliers could be shortened. Lin and Lanng [19] mentioned how supply chains could switch to alternative suppliers with technologies such as artificial intelligence and the Internet of Things when traditional sources are interfered. By being able to manage all aspects of the supply chain digitally, securely, and with transparency, it can effectively and quickly allow companies to handle any supply chain adversities.

\section{External Measures}

Government Policies/Assistance. With growing concerns to diversify supply chains during COVID-19, governments outside of China have offered some preferential policies to attract companies with manufacturing activities in China to shift their supply chains to their countries. There are also 
certain government bodies that have provided incentives for companies to move their supply chain out of China. Yu [15] pointed out how Vietnam has been giving preferential tax and land policies to attract foreign investors while the governments of US and Japan are offering financial incentives to firms to be less reliant on China as a manufacturing location.

\subsection{Medical Supply Chain}

The medical global supply chain is one of the biggest concerns during COVID-19. One of the key reasons why the medical supply chain is largely affected by COVID-19 is due to the fact that it is built on a just-in-time (JIT) philosophy [28]. Supply chains based on reliable and timely deliveries are susceptible to unforeseen disruptions on a wide scale. As the outbreak turned into a pandemic, demand for medical equipment far outweighed supplies due to the speed of infections. There were suggestions to make the medical supply chain more flexible by holding more inventory in the event of such outbreaks. However, it will be difficult for hospitals to stray away from being lean as the advantages from JIT operations are too substantial to be overlooked. Therefore, Sheffi [28] proposed having a mandated emergency inventory that would act like Federal Reserve banks. He also suggested that countries should fund the manufacturing facilities required to support reserves of critical medical supplies and to establish a unit of trained personnel to better prepare for such a disaster.

Medical devices and supplies are also increasingly reliant on China's ecosystem. During the COVID-19 outbreak, the risk of medical shortage problems became more prominent. However, Professor Yossi Sheffi from MIT [29] states that "Chinese medical products are difficult to be replaced as they are cheap and of good quality". Therefore, there is a dilemma in choosing whether to diversify the medical supply chain or to keep production in China.

China is also the world's largest producer of active pharmaceutical ingredients (API) [11]. Due to the outbreak of COVID-19, it was forced to stop industrial production of these API to contain the spread of COVID-19. Even though India leads generic development, China still makes up $70 \%$ of its inputs. This puts the pharmaceutical industry at risk as well, especially in the trying period like COVID-19 where production in China is halted or slowed down.

\subsection{Water-Energy-Food (WEF) Supply Chain}

Due to local and regional lockdowns and a virus-related reduction in the workforce, the global supply chain of water-energy-food (WEF) has faced severe challenges during the COVID-19 pandemic. Among others, the consumption and production behaviors of WEF have significantly changed. Taking food as an example, unlike non-perishable goods, the majority of agricultural commodities have expiration dates if not delivered in a timely manner. While one region suffers from certain food shortages, such as dairy items and fresh produce due to consumption increases and production interruptions, others are facing a production surplus and thus have to destroy the undeliverable items.

Additionally, availability of water resources is essential to combating the COVID-19 pandemic. While the impact of safe and clean water resources on public health has been well documented, little is known concerning the impact of catastrophic pandemic events on critical water resources. On the other hand, during the pandemic, the majority of the energy usage had been shifted from industry consumption to residential consumption after the stay-at-home order was enforced. The long-term impact of such energy consumption shifts on the supply chain of energy is uncertain at this stage.

Although response strategies of WEF in terms of climate changes are extensively studied [30], how to ensure stable supplies of WEF in response to the catastrophic public health crisis remains a worldwide concern. 


\subsection{Predictions and Preparations for the Second Wave of COVID-19}

\subsubsection{Predictions for the Second Wave of COVID-19}

There are many predictions and anticipation regarding the second wave of COVID-19. COVID-19 is a novel virus and it is difficult to ascertain how exactly it will develop unlike other infectious diseases [31]. Even so, many have tried to predict and prepare as much as possible to better position themselves for the second wave. Projections on when, where, and the magnitude of occurrence have been studied by many expert researchers.

When. Many articles have predicted the second wave to arrive during autumn and winter. Professor Gabriel Leung, dean of the University of Hong Kong's medical school, anticipated that the time needed to come up with a safe vaccine for the virus was still at least a year away, and mentioned that respiratory viruses typically spread more easily during autumn and winter [32]. Kleczkowski [33] also pointed out how the second wave could occur during autumn and winter when the incidence of the seasonal flu is expected. However, Mihalcik [34] reported that part of that forecast depends on whether the spread of virus decelerates over the summer, which does not seem to be the case now.

Where. Health experts said that the US and Europe, which hurried to relax their lockdown measures by allowing people to return to work and businesses while the pandemic is still a concern, are highly likely at risk of a second outbreak [35]. On the other hand, Bjorn Nashan, a German medical expert, told the Global Times that "the second wave can begin anywhere with insufficient immunity in the population" [35].

Scale/Magnitude. Mihalcik [34] stated that the gravity of the second outbreak would depend on numerous factors, including how well people maintain social distancing and how many people wear face masks. A study and computer model developed under Dr. De Kai, a computer scientist with appointments at both the University of California at Berkeley and Hong Kong University, indicated that if $80 \%$ of the population wore face masks in public, there will be a fall of about $8 \%$ of infections compared to not wearing any masks [34]. Basically, the more measures there are in place to aid in reducing infections and the more effectively those procedures are pursued, the lower the infection rates will be during the second wave, according to the computer model.

Certain other considerations that could come into play to determine the magnitude of the second wave of COVID-19 include any potential genetic mutations in the coronavirus that could make it more or less transmissible, the development of an effective vaccine, the development of safe, effective treatments for the COVID-19 disease, and the ability to test a significant percentage of the population, including people who do not appear to be ill [34].

There have also been studies on the pattern of the second wave of COVID-19. Woodward [36] stated that there are three scenarios that show what potential waves of COVID-19 cases could look like.

In the first scenario, the first COVID-19 wave happening now would be followed by a series of smaller waves throughout the summer and beyond. Those waves would bring a lower number of infections than the US and other countries are currently experiencing. They would continue over the next 18 to 24 months before slowly decreasing. The geographic areas in which these subsequent waves would develop based on the measures put in place and how effectively these procedures were followed.

The worst and the most likely of the three scenarios is one in which the first wave is followed by a larger wave in autumn or early winter. One or more smaller subsequent waves would arrive in 2021.

The final scenario proposes that this first wave of COVID-19 is the largest that we will see. The COVID-19 pandemic would then shift into a "slow burn" of ongoing transmission and new cases in the coming months.

As much as there are predictions regarding the second wave of COVID-19, one is not able to accurately prove that it will happen, or when or the magnitude of it when it happens. Even if the second wave does occur but of less magnitude than the first, there are still fears about the possibility and consequences of two potentially deadly viruses spreading simultaneously-the coronavirus and the seasonal flu—to our economy [34]. 


\subsubsection{Preparation for the Second Wave of COVID-19}

Move towards a Fully Digital Supply Chain

More and more companies are trying to transform their traditional supply chain models to digital supply networks (DSN). It is seen as a long-term solution to build a more resilient supply chain that can withstand disruptions like COVID-19. Bailey [37] advised to invest in the technology to automate many facets of the supply chain and drive business through algorithms that make every transaction smarter. Apart from investing in new technologies, the people aspect of the company is equally important. It is also advisable to invest in great individuals who make data-based decisions and understand analytics [37]. By increasing investments in the digital supply chain, companies can expect to explore new channels of revenue, which can also bring about higher efficiencies in business operations.

\section{Risk Management}

In light of COVID-19, businesses around the world have met with demand and supply shocks in their supply chains. McCarthy [38] highlighted the importance of possessing alternative sources of supply in the event of supply shortages or problems.

The UK government has also put risk management at the core of its return-to-work initiative. Before opening their facilities, companies are expected to perform a risk assessment, disclose it to their stakeholders, and provide proof that they are managing the defined risk effectively [39].

\section{Cross Training}

Through this pandemic, some businesses noticed additional workers were required to fill demand-related positions as well as to change products/services. Thus, businesses foresee business-wide functions where help will be needed and will conduct cross training/skilling in those areas [40].

\subsection{Focus of Our Study and Composition of the Paper}

In this paper, we address the relationship between supply chain operations and the ongoing COVID-19 pandemic. Given current global shortages in essential goods such as medication, our study pays special attention to medical supply chains and how to manage risk and cost from both short-term and long-term perspectives. Our study is the first to conceptualize a prescriptive offering for the current supply chain operations by integrating various perspectives of supply chain risk management considering the global threat caused by COVID-19. Recommendations will be given to not only mitigate current consequences in relation to the ongoing crisis, but also suggest measures that will provide firms the resiliency needed to weather similar potential shortages in the future.

The rest of this paper is organized as follows. In Section 2, we analyze the relevant issues, including the North American medical shortage and supply chain-related causes. In Section 3, we provide three recommendations, which integrate both short-term and long-term perspectives. In Section 4, we conclude this paper highlighting our contribution and potential future research topics.

\section{Issue Analysis}

Many companies with substantial supply chains operate on a multi-tier basis. This means that their supply chain operates on multiple levels, with each tier having its own groups and organizations involved. As a result, there are several supplier-to-buyer relationships within a chain which can lower costs overall, but also result in higher complexity and lowered transparency [41]. A 2017 article published in the International Journal of Production Economics asserted that when it came to multiple supply chain tiers, the sharing of information has been significantly difficult to implement much to the detriment of the cohesiveness of the overall supply chain. This lack of access to information can result in production inefficiencies, improper allocation of resources, and higher lead times [42]. These have been identified as a barrier to overall operational effectiveness. 


\subsection{Identified Issues}

North American Medical Shortage

As a result of the COVID-19 pandemic, many countries are experiencing severe shortages of medical supplies; a commodity that is highly sought after by medical professionals and citizens alike. Americans have found themselves in this predicament as a result of characteristics of their medical supply chain. In recent years, an estimated $80 \%$ of all ingredients used to produce medicine worldwide were sourced from China and India (with the former being the source of many ingredients for the latter as well) [43]. This has resulted in severe ramifications for American medical supplies since the lockdown of many industries in China and India has diminished the supply available in a time where demand is at an all-time high.

While causes such as lack of diversification is at fault, the lack of supply chain transparency is also quite problematic. The US Food and Drug Administration (FDA), for instance, was able to source and properly identify where key ingredients were coming from in order to prevent a shortage, but did not have the information required to realize that their diversified portfolio of suppliers relied on a very narrow selection of Chinese and Indian raw material suppliers themselves. As a result, while the first-tier suppliers were following strict protocols, the lower tiers were not held to the same standard [43].

Without proper information, it is extremely difficult for supply chains like that of the American medical industry to enact resilience measures that are effective to withstand situations like the COVID-19 global pandemic. This means that beyond the first-tier of suppliers, companies do not have a clear image as to what changes need to be made and what threats exist to current production capacity.

In the short-term, this issue will prove to be detrimental to the frontline healthcare workers who rely on medical supplies to operate and provide critical care; in the long-term, this issue, if unresolved, will likely be the source of greater supply chain instability and loss of resilience in years to come (which will prove especially devastating should a crisis of similar or greater scale were to happen again).

\subsection{Supply Chain-Related Causes}

\subsubsection{Lack of Supply Chain Transparency Resulting in Hindered Decision Making}

Conceptually, supply chain transparency comprises of disclosure of information on suppliers' names, sustainability, and social responsibility at each of these suppliers, to all parties in the supply chain, i.e., governments, trading partners, consumers, and other stakeholders. Note that this is different from the so-called supply chain visibility, which is defined as the extent to which the supply chain players have access to or share information which they consider as key or useful to their operations and which they consider will be of mutual benefit. In other words, supply chain transparency is supply chain visibility plus a commitment to openness and data sharing with parties within the supply chain and outside of it. Irrespective of the COVID-19 pandemic, supply chain transparency has been an issue that has been an obstacle for the evolution of supply chain operations over the years, since the reputational cost of failing to meet the information demands of the parties mentioned above can be high [44]. For instance, despite many multinational corporates attempting to introduce more sustainable and environmentally minded standards to their supply processes, a lack of transparency in the entire chain of operations means that such changes are oftentimes superficial and do not impact the multitude of tiers that substantial multi-tier supply chains are composed of [45]. In some cases, such issues have compounded into major scandals that have led to accusations of "greenwashing", resulting in damage to the reputation of many businesses. With this problem in mind, it is easy to see how this issue is one of the core factors that has plagued many organizations attempting to shift the way their supply chain operations are done in the wake of this global pandemic.

Regarding this topic, Bateman and Bonanni explain that many supply chains were initially not designed to be transparent because of fears that an abundance of information can result in the loss of 
sustainable competitive advantages [44]. By concealing data and information from partners both up and down the supply chain, each party involved in the process supposedly benefits because they do not lose the potential advantage afforded to them when it comes to negotiating prices and optimizing profit for themselves. This results in each tier of a supply chain not necessarily being united in an objective, resulting in inefficiencies caused by a fragmented organizational process.

This also ties into the idea of supply chain traceability-the idea that products and goods that go through the entire manufacturing, retail, and disposal process can be traced back to their point of origin. As mentioned before, because traditional supply chains tend to have multiple tiers that keep information kept within their own information silos, it is near-impossible to find out the process under which something has undergone despite increasingly powerful tools and methods of keeping track, such as Internet technologies and the global standards to connect every item to the web with a digital identity in the cloud [46].

When applied to the current medical supply shortage, this lack of transparency has resulted in missing shipments and lack of cooperation between purchasers (e.g., countries that need to source supplies for their own medical systems) and suppliers (e.g., factories, companies). In specific regard to the current medication crisis, many suppliers, particularly in China, have a reputation of subcontracting their work without authorization from the purchaser [47]; this trend is particularly worrying given that supply shortages are likely to occur if countries are unaware of where their desired goods are actually sourced from. For instance, the earlier example of the FDA is a key example of this. While efforts have been made to diversify supply, one of the mentioned key failures that resulted in this shortage crisis for the United States is the fact that even though the source of the completed goods themselves is made transparent to the government, the source of the materials used to produce them is not. As such, any attempts to diversify have been negated. Had there been proper transparency as to sourcing to a proper degree, there would have been more information available to make the decision more compliant with the increasingly stringent regulation.

\subsubsection{Reduced Diversification Resulting in Lack of Supply Chain Resilience}

While going for the most cost-efficient option is an option that many companies pursue, it is an option that can lead to great risk if companies are willing to sacrifice long-term resilience in favor of lowering costs. Professor Senthil Veeraraghavan of the Wharton School at the University of Pennsylvania [48] asserts that a shift towards mitigating risk through having alternate suppliers is a step forward towards improving long-term stability in the wake of crises like the COVID-19 pandemic. Many supply chains worldwide source their production and manufacturing to very limited suppliers. This cost-efficient strategy ended up being detrimental during this crisis. Companies that sourced most of their production to countries like China, for instance, found themselves crippled in terms of their production capabilities when COVID-19 resulted in government lockdowns and shutdowns of industrial hubs.

Deloitte [25] further supports the existence of this key issue, explaining that the pandemic has made many companies realize that a supply chain centered around production from one source is not sustainable, especially in this global pandemic. While sourcing raw material production to China has enabled lower costs, it has also undermined the resiliency of many supply chains worldwide who have neglected diversification due to their confidence in the stability of a single supplier.

Taking that into account, it is therefore more apparent why the world's dependence on narrow sources of medical ingredients has resulted in a global medical shortage. For instance, the FDA found that many drugs required by the US population are solely sourced to China; this has resulted in concerns over an imminent shortage given that production has been stalled for a substantial period given the Chinese government lockdown [49]. During the COVID-19 outbreak, such medical shortage problems become more prominent; Professor Yosef Sheffi from MIT notes that "medical products from China cannot easily be substituted using products from elsewhere, because they are not only low-cost, but also very good. And now we see the unfortunate consequences of this". Those unfortunate 
consequences include imminent shortages, especially regarding ventilators for patients, and masks for medical professionals and the public [29]. In addition, India, which is another major source of medical ingredients, has caused further concern as their government has announced restrictions on medical exports which is problematic given the world's dependence on not only China but India.

While the lack of diversification is not necessarily a new issue in managing supply chains, it is one that has been brought to life to an extreme degree given the unprecedented series of events that has occurred since the outbreak in Hubei province.

\subsubsection{Unsustainable Just-In-Time Manufacturing}

Given the increasingly sophisticated and optimized supply chains that are present worldwide, the ability for companies and firms to cut down costs in the production process by eliminating excessive inventory has allowed for substantial savings that help drive profitability. The just-in-time (JIT) system is an example of a framework that has continually been adopted by companies in pursuit of this objective of reducing waste.

While this is an amazing tool in times of normalcy, the ongoing COVID-19 crisis has exposed this method as being a strong cause of the current shortages worldwide. Weissman [50] asserts that the drive to lower costs nearly to the point of no excess inventory has resulted in many supply chains no longer having any backup supply during times like these-an effect that has been attributed to the fact that supply chains are now simply too tight and fragile.

\section{Recommendations}

\subsection{Nationalization of Medical Supply Chain}

In an age where most countries are attempting to source supplies for themselves through the restriction of medical exports, increasing diversification is more difficult and may not necessarily bear immediate benefits. Thus, it would be far more beneficial to focus on the shortage problem.

Professor Sean Speer [51] at the University of Toronto's Munk School of Global Affairs and Public Policy asserted the need for countries to "shockproof" themselves by moving production of essential goods. In other words, governments and companies should focus on production of supplies domestically and re-evaluate the viability of allowing for the production of most medical goods to be sourced overseas; a move that he declares an act caused by "passive acceptance of the market's pursuit of efficiency".

There is a movement in the US towards the temporary nationalization of essential medical supply chains and moving production domestically to not only ensure a stable supply, but also to ensure that the economy does not come to a standstill. In the United States, several states are petitioning the federal government to nationalize supply chain acquisitions [52]. Such a move, while potentially disruptive given private company interests, would alleviate the two aforementioned issues that has amplified the current shortage crisis.

The nationalization of supply chains has several benefits that can improve the efficiency and production of medical supplies. Lack of information and transparency has resulted in many problems for the medical supply chain, so by merging information under federal oversight, this allows for an unprecedented amount of information that can be used towards the allocation and distribution of key resources. This could also accelerate supply movement and help alleviate shortages given that bottlenecks can be eliminated as the national effort to procure supplies consolidates. By federally mandating transparency and inducing harsh penalties for companies that flout government directives through direct control of essential supply chains, it is possible for nations to take these severe measures to counter the growing problem of dwindling quantities of essential goods.

Although seemingly radical, this approach is one that some politicians and experts have been exploring in response to the current supply chain crisis with specific regard to the medical supply shortage. Germany's Economy Minister Peter Altmaier commented that given the COVID-19 pandemic, 
a move towards nationalizing pharmaceutical production is not out of the question and that the production of medical supplies on a national level would be essential to "winning back national sovereignty in sensitive areas" [53]. In the United States, Senator Chris Murphy responded to President Donald Trump's comments in regard to potentially using the nation's Defense Production Act as a threat to compel companies to boost production of medical supplies, stating that such actions needed to be bolstered by having the government completely nationalize the supply process of these essential goods [54].

Whether the nationalization of key industries is permanent depends on the situation post-pandemic. Countries like Canada have a history of nationalizing industries and companies to control the market. These countries also ensure that undesirable economic outcomes are averted using Crown Corporations, which are companies owned and oftentimes formed by the government [55]. These organizations serve as a means for the government to provide services and goods for the public that may not necessarily be feasible under private ownership; this provides social utility for Canadians as it fills gaps in public needs that are insufficiently fulfilled by private forces. Once government oversight has been deemed unnecessary (for instance, in the case of the passing of a unique event like an economic recession), these corporations are sometimes privatized-as in the case of Canada's gasoline, telecommunications, and airline industries [56]. What this illustrates is the potential for medical supply chains to either be temporarily or permanently nationalized depending on the situation post-pandemic. If the need for a consolidated pharmaceutical industry under government oversight is seen as being essential to ensuring that supply chains do not collapse or experience shortages in the wake of a potential future pandemic, then it would not be surprising that nationalization becomes a permanent fix for the medical supply sourcing of many countries.

\subsection{Adoption of "Plus One" Diversification Approach}

Way before the COVID-19 pandemic, many supply chain managers had adopted the so called "plus one" approach to manage the risk of over-concentration of companies in China. This strategy suggests the companies to diversify their investments into other countries instead of investing only in China as a safer long-term strategy. In addition to risk management, with the cost of doing business in China rising over the years, this approach can also bring companies a potentially more economical option in the long run.

As such, while the nationalization of the medical supply chain will ideally alleviate the immediate issue of a shortage by mitigating its effects, the long-term viability of a fully domestic-based production is questionable at best. Regardless of whether the supply chain remains nationalized or is eventually privatized once the pandemic subsides (as in the case of Canada, where many government-owned industries are slowly sold off to and maintained by private individuals), lack of diversification will still be an issue.

Once the COVID-19 pandemic has been resolved and the world begins the process of recovering from the economic downturn, it will become far more prudent for governments and companies to conduct a cost-benefit analysis of sourcing from a narrow selection of producers and suppliers.

It is unlikely that the global supply chain's reliance on major producers such as China will be shifted for decades to come; however, it is also likely that the pandemic will be a catalyst for further measures to be taken in order to prevent the catastrophic shortage that is occurring now. Since lowering costs will continue to be a key benefit of the current global supply chain's organization and structure, it is therefore recommended that countries and companies pursue a "plus one" approach to diversification in the supply chain.

The "plus one" approach applies primarily to the current global supply chain situation which, even if taken from a non-medical supply context, is heavily dependent on the relatively cheap production and sourcing opportunities available from China. This strategy was initially proposed to mitigate the potential risk of rising costs from Chinese production but has since been adopted to spread out the likelihood of environmental and operational risks present from such a narrow stream 
of supply. To accomplish this, multinational companies will also invest in production and sourcing from countries that are located near the main source of production; which in this case would be the surrounding Asian countries near China [57].

It is important to note that in the context of the current pandemic, this does not mean permanently shifting nearly all production from out of China. This is merely a means of lowering dependencies; a complete movement from Chinese production would not be effective as this would effectively remove all the advantages that come from the country's already fledging infrastructure and industry.

This recommendation also has other key benefits in addition to limiting potentially restrictive dependencies. For China specifically, the global supply chain has initiated an unprecedented level of growth in Chinese industries, which has resulted in the country's status as a transitional economy. Governments that are looking towards a market economy will oftentimes, as in the case of the Chinese, provide incentives towards local businesses and national needs; a move that causes competition and lowered benefits for companies looking to source from the country. It can therefore be asserted that the cost advantages of Chinese production will likely be lowered as time goes on. A "plus one" strategy enables a diversification strategy that is able to have alternatives that can be quickly used should this occur.

It is interesting to note that one potential advantage of this "plus one" approach is also the initiation of enhanced competitiveness between supplying nations. In other words, by moving investments to other countries for production (such as Vietnam), it signals to nearby nations that there is a potential economic opportunity available that was previously entirely overtaken by major production-heavy nations like China. This incentivizes countries to introduce investor-friendly initiatives and enhance production efficiency to capitalize on the market demand. Such a move would therefore enable the advantage of low costs from multiple sources instead of one [57]. This would potentially drive down costs and give governments and companies the advantage of lower production costs without the disadvantage of low diversity.

Of course, in the event that a similar pandemic occurs, countries may once again begin locking down their industries and restrict exports. This will undoubtedly cause an impact with supply chains; after all, there are few viable solutions that would be able to completely negate the consequences and risks of a massive event like the COVID-19 outbreak. However, by not allowing supply chains to be completely integrated into one market, it allows time for countries to take on pre-emptive measures during the early days of a pandemic as the likelihood of shutdowns would be spread out among several suppliers.

This solution is not without its drawbacks. Given that the "plus one" approach is centered around diversifying production by enhancing supply chain investment in nearby areas, it is important to note that this often means having to rely on less developed nations that have varying levels of safety and legal power. The initial phase of shifting production will likely have incidents of potential unauthorized third parties [58]. Not to mention, when an organization sources production from new countries, it likely needs to adapt to different business cultures from what it has already been used to, hence incurring extensive research and start-up costs.

\subsection{Increasing Safety Stock}

Finally, the issue of shortages can be mitigated in the future by implementing the rather obvious solution of increasing safety stock. The JIT mindset is one that is capable of lowering costs, but it is also one that has resulted in lowered resiliency in the face of crises like the COVID-19 pandemic. Industries have spent years optimizing their supply chains, removing processes that may slow down the process, and eliminating manufacturing perceived as potentially wasteful. However, this outbreak may be a sign that having a more tight and lean supply chain is not necessarily the best option despite it being a theoretically optimal method of running profitable supply chains.

In an article from the University of Guelph, Professor Evan Fraser asserts that it may be necessary for supply chains to purposefully build in redundancies and buffers in order to weather major 
disruptions [59]. It is noted that while JIT has enabled lower costs of goods for many companies, it is also an approach that is pursued by many suppliers that are part of the supply chain. Because trade has been globalized to the point where organizations are completely dependent on goods and supplies from areas outside of their local vicinity, loss of resilience occurs and negatively affects their ability to operate when these supply chains face major disruptions somewhere along the process.

This ties in with the previously mentioned idea of an overdependence on too narrow of a selection of suppliers. Not only do supply chains need to diversify to prevent another shortage like the ones currently experienced in the wake of this crisis, they also need to implement measures to enable a level of self-sufficiency during times of disruption so that organizations can continue to function until recovery can begin.

\section{Conclusions}

To conclude, the COVID-19 pandemic is an unprecedented event in the 21st century in terms of its scope and effect on supply chain logistics. Had it not occurred, flaws and issues that were identified earlier may never have reached the level of awareness that is causing many firms, governments, and companies to reconsider their options and decisions heading into this era. While a mitigation of the current shortages is an immediate concern that should be accomplished as soon as possible, it is also important to prepare for a post-pandemic landscape that may continue to feel the effects of this crisis for many years to come.

Given the relationship between the medical shortage and supply chain issues during the COVID-19 pandemic, this paper proposes recommendations to protect supply chain operations. For countries that highly depend on China or India for supply, we suggest two measures. First, nationalize the acquisition of medical supplies. This measure can improve efficiency and production of medical supply for two reasons-it not only enhances supply chain transparency and hence optimizes allocation of key resources, but also accelerates supply movement since bottlenecks can be eliminated as the national effort to procure supplies consolidates. Second, these companies should seek alternate sources of supply, such as investing in production and sourcing from countries that are located near the main source of production.

The dominance of certain suppliers in the market and their ability to lower costs for supply chains must now be carefully balanced against their potential lack of versatility and flexibility. Although the appeal of diversifying and reducing dependencies is becoming more attractive in the wake of this crisis, it is also important to understand the new political positions that may occur as a result. With two of the most powerful nations in the world, the United States and China, now experiencing a highly tense relationship, this dynamic will likely have future ramifications for supply chain planning for many parties both within and outside of those nations.

Our paper is the first to conceptualize a prescriptive offering for the current supply chain operations by integrating various perspectives of supply chain risk management considering the global threat caused by COVID-19. Our focus is on a strategic-level conceptualized model for risk management instead of deriving managerial insights from detailed supply chain data. When more detailed supply chain data become available in the future, analytical models and empirical studies can be conducted for a better understanding on issues at the tactical and operational levels. A comparison between countries would also be a good topic for future research when more data are available. In addition, our study focuses on issues related to COVID-19 and pays special attention to medical supply chains. A comparison on these issues with previous pandemics or other supply chain types would be a good direction for future research.

Author Contributions: Conceptualization, M.C.C.; methodology, G.Z. and M.C.C.; software, G.Z. and M.C.C.; validation, C.W.T.; formal analysis, G.Z. and M.C.C.; investigation, G.Z. and M.C.C.; resources, M.C.C.; data curation, G.Z.; writing—original draft preparation, G.Z. and M.C.C.; writing—review and editing, G.Z., M.C.C. and C.W.T.; visualization, G.Z. and M.C.C.; supervision, M.C.C. and C.W.T.; project administration, M.C.C. and C.W.T.; funding acquisition, M.C.C. and C.W.T. All authors have read and agreed to the published version of the manuscript. 
Funding: The authors would like to thank the Ministry of Science and Technology of Taiwan for financially supporting this study under contract number 108-2221-E-002-011-MY3.

Acknowledgments: The authors would like to thank the editor and three anonymous referees for their valuable comments and suggestions that helped improve this paper.

Conflicts of Interest: The authors declare no conflict of interest.

\section{References}

1. Bloomberg. The Coronavirus Is Infecting the Global Economy. Here's How. Available online: https://www. bloomberg.com/news/articles/2020-01-31/the-global-economy-is-getting-infected-by-the-virus (accessed on 31 January 2020).

2. National Post. It's Official: 'Deeply Concerned' WHO Declares the COVID-19 Outbreak a Global Pandemic. Available online: https://nationalpost.com/news/world/its-official-the-covid-19-outbreak-is-aglobal-pandemic (accessed on 11 March 2020).

3. Supply Chain Digital. Accenture: Building Supply Chain Resilience Amidst COVID-19. Available online: https://www.supplychaindigital.com/supply-chain-management/accenture-building-supply-chainresilience-amidst-covid-19 (accessed on 2 April 2020).

4. International Civil Aviation Organization. Economic Impacts of COVID-19 on Civil Aviation. Available online: https://www.icao.int/sustainability/Pages/Economic-Impacts-of-COVID-19.aspx (accessed on 29 June 2020).

5. United Nations Conference on Trade and Development. Global Trade Update. Available online: https: //unctad.org/en/pages/newsdetails.aspx? OriginalVersionID=2392 (accessed on 11 June 2020).

6. Hub. Johns Hopkins University. How Coronavirus Will Affect the Global Supply Chain. Available online: https://hub.jhu.edu/2020/03/06/covid-19-coronavirus-impacts-global-supply-chain/ (accessed on 6 March 2020).

7. IMD. How Supply Chains Are Adapting to the COVID-19 Lockdowns. Available online: https://www.imd. org/research-knowledge/articles/supply-chains-adapting-to-covid-19/ (accessed on 25 March 2020).

8. World Economic Forum. COVID-19 Threatens Global Supply Chains. We Must Act Now. Available online: https://www.weforum.org/agenda/2020/05/global-supply-chains-are-under-imminent-threat-fromthe-covid-19-pandemic/ (accessed on 5 May 2020).

9. Vietnam Briefing. Q\&A: COVID-19 and Response to Supply Chain Disruption in Vietnam. Available online: https:/www.vietnam-briefing.com/news/qa-covid-19-response-supply-chain-disruption-vietnam. html/ (accessed on 18 May 2020).

10. Vijay Govindarajan, G.B. As Covid-19 Disrupts Global Supply Chains, Will Companies Turn to India? Available online: https://hbr.org/2020/05/as-covid-19-disrupts-global-supply-chains-will-companies-turnto-india (accessed on 25 May 2020).

11. Oxford Business Group. The Impact of Covid-19 on Global Supply Chains. Available online: https: //oxfordbusinessgroup.com/news/impact-covid-19-global-supply-chains (accessed on 24 April 2020).

12. The Japan Times. Can the U.S. End China's Control of the Global Supply Chain? Available online: https: //www.japantimes.co.jp/news/2020/06/09/business/u-s-china-global-supply-chain/ (accessed on 9 June 2020).

13. AXA IM Singapore. The World's Factory in COVID-19: Can China Secure its Supply Chain Kingdom? Available online: https:/www.axa-im.com.sg/content/-/asset_publisher/FehknnI2EsIG/content/the-world-sfactory-in-covid-19-can-china-secure-its-supply-chain-kingdom-/26520 (accessed on 18 May 2020).

14. The Japan Times. China Factory Output Rises. Available online: https://www.japantimes.co.jp/news/2020/05/ 15/business/economy-business/china-factory-output-rises-april/ (accessed on 15 May 2020).

15. Maplecroft. Pandemic Quickens Supply Chains Diversification Beyond China. Available online: https://www.maplecroft.com/insights/analysis/pandemic-quickens-diversification-of-supply-chainsbeyond-china/ (accessed on 2 July 2020).

16. Bakermckenzie. Beyond COVID-19: Supply Chain Resilience Holds Key to Recovery. Available online: https: //www.bakermckenzie.com/-/media/files/insight/publications/2020/04/covid19-global-economy (accessed on 8 April 2020).

17. Material Handling and Logistics. Impact of the Coronavirus on Global Supply Chain. Available online: https://www.mhlnews.com/global-supply-chain/article/21122993/impact-of-the-coronavirus-onglobal-supply-chain (accessed on 14 February 2020). 
18. Medium. Are You Prepared to Manage A Whack-A-Mole Recovery? Available online: https://medium. com/mitsupplychain/are-you-prepared-to-manage-a-whack-a-mole-recovery-6b79127ad63a (accessed on 30 April 2020).

19. World Economic Forum. Here's How Global Supply Chains Will Change After COVID-19. Available online: https://www.weforum.org/agenda/2020/05/this-is-what-global-supply-chains-will-look-like-aftercovid-19/ (accessed on 6 May 2020).

20. SGS.ME. The Effects of COVID-19 on Global Supply Chains: Short Term Pain but Potential Long Term Benefits. Available online: https://www.sgsme.sg/news/effects-covid-19-global-supply-chains-short-termpain-potential-long-term-benefits (accessed on 14 May 2020).

21. Source Today. The Impact of COVID on Global Supply Chain and Logistics. Available online: https://www.sourcetoday.com/supply-chain/article/21134577/the-impact-of-covid-on-global-supplychain-and-logistics (accessed on 19 June 2020).

22. Analytics. Keys to mitigating supply chain disruptions related to coronavirus. Analytics Magazine News, 2020. [CrossRef]

23. Sheffi, Y. Who Gets What When Supply Chains Are Disrupted? MIT sloan Manag. Review. 2020. Available online: https://sloanreview.mit.edu/article/who-gets-what-when-supply-chains-are-disrupted/ (accessed on 27 May 2020).

24. Vietnam Briefing. COVID-19 and the Effects on Supply Chains in Vietnam. Available online: https: //www.vietnam-briefing.com/news/covid-19-effects-supply-chains-vietnam.html/ (accessed on 24 June 2020).

25. Deloitte. COVID-19: Managing Supply Chain Risk and Disruption. Available online: https://www2. deloitte.com/ca/en/pages/finance/articles/covid-19-managing-supply-chain-risk-and-disruption (accessed on 10 March 2020).

26. Medium. How the Pandemic Could Remake Supply Chain's Digital Future. Available online: https://medium.com/mitsupplychain/how-the-pandemic-could-remake-supply-chains-digitalfuture-83332a9847bd (accessed on 30 April 2020).

27. Wuest, T.; Kusiak, A.; Dai, T.; Tayur, S.R. Impact of COVID-19 on Manufacturing and Supply Networks-The Case for AI-Inspired Digital Transformation. Available on SSRN 3593540 2020, 47, 3. Available online: https://papers.ssrn.com/sol3/papers.cfm?abstract_id=3593540 (accessed on 30 April 2020).

28. MIT Center for Transportation and Logistics. Commentary: Solving the Health-Care Equipment Supply Shortage. Available online: https:/www.wsj.com/articles/commentary-solving-the-health-care-equipmentsupply-shortage-11586512801?mod=searchresults (accessed on 10 April 2020).

29. MIT News. Supply Chain Outlook: Why the Situation Varies by Industry. Available online: http: //news.mit.edu/2020/sheffi-global-supply-chain-covid-19-0325 (accessed on 25 March 2020).

30. Vuuren, D.P.V.; Bijl, D.L.; Bogaart, P.; Stehfest, E.; Biemans, H.; Dekker, S.C.; Doelman, J.C.; Gernaat, D.E.H.J.; Harmsen, M. Integrated scenarios to support analysis of the food-energy-water nexus. Nat. Sustain. 2019, 2, 1132-1141. [CrossRef]

31. HuffPost. Experts Predict What A Second Wave of Coronavirus Will Be Like. Available online: https://www. huffpost.com/entry/experts-predict-second-wave-coronavirus_1_5ef0b6d8c5b639909d574e7c (accessed on 23 June 2020).

32. South China Morning Post. Hong Kong Professor Calls for Genomic Sequencing of Every Covid-19 Case So Far. Available online: https://www.scmp.com/news/hong-kong/health-environment/article/3088602/ coronavirus-hong-kong-goes-week-without-any-local (accessed on 11 June 2020).

33. World Economic Forum. Coronavirus: What A Second Wave Might Look Like. Available online: https: //www.weforum.org/agenda/2020/06/coronavirus-second-wave/ (accessed on 4 June 2020).

34. Cnet. Fauci: US Going in 'Wrong Direction' as Coronavirus Cases Rise. Available online: https://www.cnet. com/news/fauci-us-going-in-wrong-direction-as-coronavirus-cases-rise/ (accessed on 30 June 2020).

35. Global Times. Protests, Work Resumption Add to Concern of 2nd COVID-19 Wave. Available online: https://www.globaltimes.cn/content/1190978.shtml (accessed on 8 June 2020).

36. Business Insider. Anthony Fauci Says There's 'Virtually No Chance' the Coronavirus Will Disappear-3 Charts Predict What Future Waves of Cases Will Look Like. Available online: https://www.businessinsider. com/second-wave-of-coronavirus-infections-may-peak-in-fall-2020-5 (accessed on 14 May 2020). 
37. Forbes. Is Your Supply Chain Ready for A Second Wave of COVID-19? Available online: https://www.forbes. com/sites/georgebailey1/2020/06/02/is-your-supply-chain-ready-for-a-second-wave-of-covid-19/ (accessed on 2 June 2020).

38. Abc News. How Food Producers Are Preparing for the 2nd Wave Of COVID-19. Available online: https: //abcnews.go.com/Business/food-producers-preparing-2nd-wave-covid-19/story?id=71277758 (accessed on 17 June 2020).

39. Treasury and Risk. 3 Steps to Prepare for Reopening-And for Covid-19's Second Wave. Available online: https://www.treasuryandrisk.com/2020/06/30/3-steps-to-prepare-for-reopening-and-for-covid-19ssecond-wave/?slreturn=20200606134508 (accessed on 30 June 2020).

40. ChiefExecutive.net. Preparing Your Workforce for A Second Wave Of COVID-19. Available online: https: //chiefexecutive.net/preparing-your-workforce-for-a-second-wave-of-covid-19/ (accessed on 8 May 2020).

41. Cgnglobal. Multi-Tier Supply Chain Visibility. Available online: https://www.cgnglobal.com/blog/multi-tiersupply-chain-visibility (accessed on 17 February 2019).

42. Kembro, J.; Näslund, D.; Olhager, J. Information sharing across multiple supply chain tiers: A Delphi study on antecedents. Int. J. Prod. Econ. 2017, 193, 77-86. [CrossRef]

43. Supply Chain Dive. How Medical Supply Chains Can Diversify Beyond COVID-19. Available online: https: //www.supplychaindive.com/news/coronavirus-health-pharma-medical-costdiversify/576021/ (accessed on 15 April 2020).

44. Bateman, A.; Bonani, L. What Supply Chain Transparency Really Means. Harvard Bus. Rev. 2019. Available online: https://hbr.org/2019/08/what-supply-chain-transparency-really-means (accessed on 20 August 2019).

45. Villena, V.H.; Gioia, D.A. A More Sustainable Supply Chain. Harvard Bus. Rev. 2020. Available online: https://hbr.org/2020/03/a-more-sustainable-supply-chain (accessed on 30 April 2020).

46. World Economic Forum. COVID-19 Revealed the Need for A Globally-Connected Supply Chain. Available online: https://www.weforum.org/agenda/2020/04/covid-19-globally-connected-supply-chainsystem-interoperability-whitepaper/ (accessed on 17 April 2020).

47. Omega Compliance. CASE STUDY: UNAUTHORIZED SUBCONTRACTING IN CHINESE SUPPLY CHAINS. Available online: https://www.omegacompliance.com/subcontracting/ (accessed on 5 April 2016).

48. Knowledge@wharton. Coronavirus and Supply Chain Disruption: What Firms Can Learn. Available online: https://knowledge.wharton.upenn.edu/article/veeraraghavan-supply-chain/ (accessed on 17 March 2020).

49. Vox. Could the Coronavirus Spark Drug Shortages in the US? Available online: https://www.vox.com/2020/ 3/9/21163356/coronavirus-drug-shortage-potential-fda-china-india (accessed on 9 March 2020).

50. Supply Chain Dive. Today's Supply Chains Are Too Lean. Available online: https://www.supplychaindive. com/news/lean-supply-chain-jit-inventory-covid-19/574693/ (accessed on 24 March 2020).

51. National Post. Shock Proofing Canada: COVID-19 Makes it Clear We Must Repatriate PPE Production. Available online: https://nationalpost.com/opinion/shockproofing-canada-covid-19-makes-it-clear-we-mustrepatriate-ppe-production (accessed on 17 April 2020).

52. The National Law Review. Free for All, or All for One? The Medical Supply Chain and COVID-19. Available online: https://www.natlawreview.com/article/free-all-or-all-one-medical-supply-chain-andcovid-19 (accessed on 23 March 2020).

53. Financial Post. Germany Would Like to Localize Supply Chains, Nationalization Possible-Minister. Available online: https://business.financialpost.com/pmn/business-pmn/germany-would-like-to-localizesupply-chains-nationalization-possible-minister (accessed on 13 March 2020).

54. Yahoo. Murphy: Private Market Is Failing, Health Care Workers in 'Absolute Panic' Over Supply Shortages. Available online: https://ca.finance.yahoo.com/news/sen-murphy-private-sector-is-failinghealthcare-workers-in-absolute-panic-over-supply-shortages-224959580.html (accessed on 23 March 2020).

55. Canada.ca. Guidance for Crown Corporations. Available online: https://www.canada.ca/en/treasury-boardsecretariat/services/guidance-crown-corporations.html (accessed on 18 April 2019).

56. CBC.ca. What are Crown Corporations and Why Do They Exist? Available online: https://www.cbc.ca/news/ canada/what-are-crown-corporations-and-why-do-they-exist-1.1135699 (accessed on 1 April 2012).

57. Enderwick, P. A ‘China-Plus-One’ strategy: The Best of Both Worlds? Hum. Syst. Manag. 2011, 30, 85-96. [CrossRef] 
58. The Magazine of the British Chamber of Commerce in Japan. China Plus One. Available online: https: //bccjacumen.com/china-plus-one/ (accessed on 17 May 2011).

59. Arrell Food Institute. COVID-19: The Perils of A 'Just Enough, Just in Time' Food System. Available online: https://arrellfoodinstitute.ca/covid-19-food-system/ (accessed on 16 March 2020).

(C) 2020 by the authors. Licensee MDPI, Basel, Switzerland. This article is an open access article distributed under the terms and conditions of the Creative Commons Attribution (CC BY) license (http://creativecommons.org/licenses/by/4.0/). 